\title{
Evaluation of partially premixed turbulent flame stability from mixture fraction statistics in a slot burner
}

S. Kruse, M.S. Mansour, A.M. Elbaz, E. Varea, G. Grünefeld, J. Beeckmann, and H. Pitsch

\section{QUERY SHEET}

This page lists questions we have about your paper. The numbers displayed at left can be found in the text of the paper for reference. In addition, please review your paper as a whole for correctness.

Q1: $\quad$ Au: Please supply full names for all authors as this is required by journal style.

Q2: $\quad A u$ : Please provide missing city name for affiliations "c" and " $\mathrm{d}$ ".

Q3: Au: Please provide missing department name for affiliation " $\mathrm{f}$ "

Q4: $\quad$ Au: Please check whether the head levels are set correctly.

Q5: Au: Please confirm whether the reference citation [Mansour et al. (2017b)] as placed is set correctly.

Q6: $\quad \mathrm{Au}$ : Please provide missing [editor name or institutional editor name, publisher name and publisher location] for [Mansour and Masri, 2017].

\section{TABLE OF CONTENTS LISTING}

The table of contents for the journal will list your paper exactly as it appears below:

Evaluation of partially premixed turbulent flame stability from mixture fraction statistics in a slot burner

S. Kruse, M.S. Mansour, A.M. Elbaz, E. Varea, G. Grünefeld, J. Beeckmann, and H. Pitsch 


\title{
Evaluation of partially premixed turbulent flame stability from mixture fraction statistics in a slot burner
}

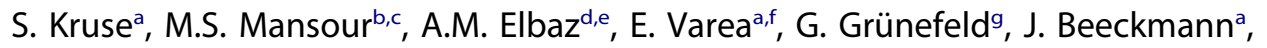 \\ and H. Pitsch ${ }^{\mathrm{a}}$
}

alnstitute for Combustion Technology, RWTH Aachen University, Aachen, Germany; ${ }^{\mathrm{b} M e c h a n i c a l ~ E n g i n e e r i n g ~}$ Department, The American University in Cairo, New Cairo, Egypt; 'Mechanical Power Engineering Department, Faculty of Engineering, Cairo University, Egypt; ${ }^{\mathrm{d} C l e a n}$ Combustion Research Center, King Abdullah University for Science and Technology, Saudi Arabia; ${ }^{\mathrm{E}}$ Faculty of Engineering- Mataria, Helwan

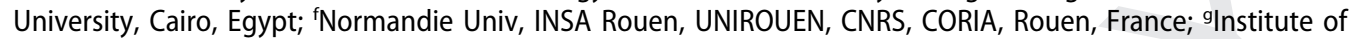
Technical Thermodynamics, RWTH Aachen University, Aachen, Germany

\begin{abstract}
Partially premixed combustion is characterized by mixture fraction inhomogeneity upstream of the reaction zone and occurs in many applied combustion systems. The temporal and spatial fluctuations of the mixture fraction have tremendous impact on the combustion characteristics, emission formation, and flame stability. In this study, turbulent partially premixed flames are experimentally studied in a slot burner configuration. The local temperature and gas composition is determined by means of one-dimensional, simultaneous detection of Rayleigh and Raman scattering. The statistics of the mixture fraction are utilized to characterize the impact of the Reynolds number, the global equivalence ratio, the progress of mixing within the flame, as well as the mixing length on the mixing field. Furthermore, these effects are evaluated by means of a regime diagram for partially premixed flames. In this study, it is shown that the increase of the mixing length results in a significantly more stable flame. The impact of the Reynolds number on flame stability is found to be minor.
\end{abstract}

\section{ARTICLE HISTORY}

Received 21 September 2017

Revised 9 January 2018

Accepted 1 March 2018

\section{KEY WORDS}

Partially premixed flame; flame stability; turbulent combustion; line-Raman measurement; Rayleigh measurements; turbulent slot burner

\section{Introduction}

The combustion behavior and the flame stability are significantly influenced by the mixing characteristics of air and fuel upstream of the flame. In combustion research, flames are typically classified based on fuel and air mixing as premixed and non-premixed flames. For premixed flames, fuel and air are perfectly mixed upstream of the reaction zone, and mixture fraction gradients are absent. The flame propagates into the unburnt fuel/air mixture and the reaction zone is located at the position where the flame-normal velocitycomponent of the unburnt gas stream equals the burning velocity of the flame. Laminar premixed flames are controlled by the interaction of reaction kinetics and transport and are mainly characterized by the laminar burning velocity as well as the flame thickness. In order to describe the interaction of premixed combustion with turbulence, Peters (Peters, 2000) classified different regimes by normalized length and velocity scales. To obtain the non-dimensional parameters, the turbulent flame speed and the turbulent length scale are 
normalized by the laminar flame speed and the laminar flame thickness, respectively (Borghi, 1988; Peters, 2000). For non-premixed flames, mixing of fuel and air is often the rate-determining process. Air and fuel are introduced separately to the burner and the reactions occur at the location of stoichiometric mixture fraction.

While the premixed and non-premixed flame types are highly relevant for fundamental combustion research, partially premixed combustion is prevalent in many practical combustion systems. Partially premixed combustion is found in diesel engines, direct injection stratified charge engines (Aleiferis et al., 2004; Dec, 2009), and gas turbines (Huang and Yang, 2009) where mixture fraction gradients enhance efficiency and lower emissions (Masri, 2015). Partially premixed flames are characterized by large fluctuations of the local mixture fraction covering ranges inside and outside the flammability limits (Masri, 2015). Thus, modeling of partially premixed flames is highly complex.

The partial mixing of air and fuel is generated either by the inlet conditions of the burner (Mansour et al., 2017a; Meares and Masri, 2014) or by additional air entrainment between the burner exit and the base of the lifted flames (Favier and Vervisch, 1998; Joedicke et al., 2005). For fundamental investigations of partially premixed flames, a burner concept to vary the degree of premixing has been proposed by Lee et al. (1997) and Mansour (2000). The burner consists of two concentric tubes, in which the inner one is traversable in order to change the length for air and fuel mixing upstream the burner exit. While Mansour (2000) used a conical nozzle at the burner exit to stabilize the flame, Meares and Masri (2014) introduced a similar burner concept with a pilot burner for flame stabilization. In this study, a slot burner design is utilized to investigate the mixture fraction fluctuations in partially premixed flames. Recently, a concept for partially premixed flame investigations based on a slot burner design has been introduced by Mansour et al. (2017b). Due to the two-dimensional flame property, slot burners have been widely used for investigations considering turbulent premixed flames (Filatyev et al., 2005), diffusion flames (Branco et al., 2016), and stratified flames (Barlow et al., 2009).

The characteristics and structures of partially premixed flames have been studied by means of advanced laser-based optical measurement techniques (Barlow et al., 2017; Elbaz et al., 2018, 2016; El-Mahallawy et al., 2007; Li et al., 2009; Mansour et al., 1989; Mansour et al., 2017a; Mansour et al., 2012; Meares et al., 2015; Meares and Masri, 2014; Yan et al., 2010) and experimental data were used to analyze the dependences of the degree of premixing (Meares et al., 2015; Meares and Masri, 2014) and the impact of different fuel compositions on flame stability (Yan et al., 2010). Lasers have been applied for example for Rayleigh/Raman measurements to determine local temperature and gas composition in flames (Barlow et al., 2009; Brands et al., 2014; Cheng et al., 2012; Fuest et al., 2011, 2015, 2012; Mansour et al., 1999; Mansour and Yung-Cheng, 1996; Raffius et al., 2017; Wehrmeyer et al., 1992). Moreover, comparisons of computed and measured partially premixed flame structures and dynamics have been performed in order to examine modeling approaches for flame stabilization. Recently, Barlow et al. (2017) proposed a new progress variable defined as the local ratio of the oxygen bound in the main products and the oxygen bound if the local gas sample would be in equilibrium.

While experiments analyzing partially premixed flame properties and stability are available for a wide range boundary conditions, experimental data sets linking flame stability with the main quantities characterizing fuel-air mixing, namely the mixture fraction and its statistics, are deficient. Mansour (2016) has recently proposed a regime 
diagram in order to quantify the stability of partially premixed flames based on the statistics of mixture fraction. The mixture fraction fields of various partially premixed flames in a concentric flow conical burner determined by means of Rayleigh scattering have been investigated by Mansour et al. (2017a). Correlations of the mixing field and the flame stability have been identified, where the mixing length and the equivalence ratio are found to be dominant parameters to affect flame stability (Mansour et al., 2017a).

The current study aims to investigate the statistics of the mixture fraction to characterize (1) the impact of the Reynolds number, (2) the global equivalence ratio, (3) the progress of mixing within the flame, and (4) the mixing length on the mixing field. Collected data are analyzed and summarized in a regime diagram for partially premixed flames.

\section{Experimental setup}

This section provides details of the burner concept and the optical setup for the simultaneous detection of the Raman and Rayleigh signals. Moreover, the post-processing approach to determine the mixture fraction is briefly discussed.

\section{Burner design}

For this study, a slot burner configuration is used to investigate the impact of the degree of fuel and air premixing as well as the Reynolds number on the mixture fraction fluctuations and thereby on the flame stability. Details of the burner design are shown in Figure 1.

The burner consists of an outer slot and a recessed inner slot. Both slots share the same centerline. The air flows through the outer slot while fuel issues from the inner slot. The recessed distance, $l$, is adjusted to 48 and $96 \mathrm{~mm}$ in order to create partially premixed jets with different degrees of mixture inhomogeneity at the exit of the outer slot. The dimensions of the exit of the outer slot are $100 \mathrm{~mm}$ length and $12 \mathrm{~mm}$ width, $d$, while the inner slot dimensions are $100 \mathrm{~mm}$ length and $1 \mathrm{~mm}$ width. Laminar pilot flames are used at both sides of the nozzle exit to stabilize the turbulent flames. The pilot dimensions are $100 \mathrm{~mm}$ length and $24 \mathrm{~mm}$ width at both sides of the outer slot. For the pilot flames,

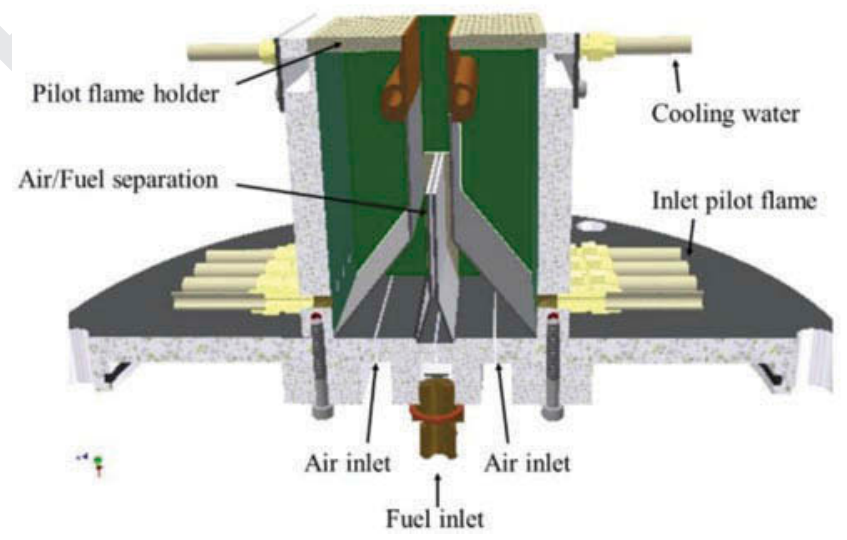

Figure 1. Slot burner setup for partially premixed flame investigation. 
methane from a gas bottle (purity 99.5\%) and compressed air are mixed upstream of the burner inlet. The flow rates of fuel and air are controlled by laminar flow element mass flow controllers (MFCs) Omega FMA2606 (uncertainty $0.8 \%$ on set point (SP) and $0.2 \%$ on full scale (FS)) and Omega FMA2609 (uncertainty $0.8 \%$ on SP and $0.2 \%$ on FS), respectively. The flow rates are set to achieve stoichiometric flame conditions and a cold gas velocity of $0.35 \mathrm{~m} / \mathrm{s}$ at the slot exits. Perforated ceramic plates with hole diameter of $0.5 \mathrm{~mm}$ and a blocking ratio of $50 \%$ serve as flame holders at the side slit exit. Thermal MFCs Omega FMA5543 and FMA5545 were used for the main fuel and air, respectively. The accuracy of both MFCs is $3 \%$ for flow rates in the range of $0-20 \%$ of the FS and $1.5 \%$ of the FS for higher flow rates.

\section{Line Raman-Rayleigh technique}

A one-dimensional Raman-Rayleigh technique is used for simultaneous line measurements of species concentrations, mixture fraction, and temperature. A schematic of the optical setup is presented in Figure 2.

A tunable KrF-Excimer laser (Lambda Phyiscs EMG250) is used as the light source. The emitted laser beam has a rectangular shape of $22 \mathrm{~mm}$ height and $10 \mathrm{~mm}$ width with $225 \mathrm{~mJ} /$ pulse energy. The laser wavelength is adjusted to $248.415 \mathrm{~nm}$ with $\sim 0.001 \mathrm{~nm}$ linewidth in order to avoid any laser-induced fluorescence excitation. The laser beam is guided by a highly reflective mirror to the burner setup and is focused by a spherical, plano-convex, 300-mm focal length lens above the burner exit. The dimensions of the laser beam in its focal point are determined from burn patterns on optical paper and are found to be $0.4 \mathrm{~mm}$ in height and $0.2 \mathrm{~mm}$ in width. The laser beam crosses the burner in radial direction, whereas the detection system is located perpendicular to the laser beam path at the front end of the burner. The scattered light is collected by a plano-convex, spherical lens $(f=200 \mathrm{~mm})$ and then mapped by a second plano-convex lens $(f=180 \mathrm{~mm})$ on the spectrograph slit.

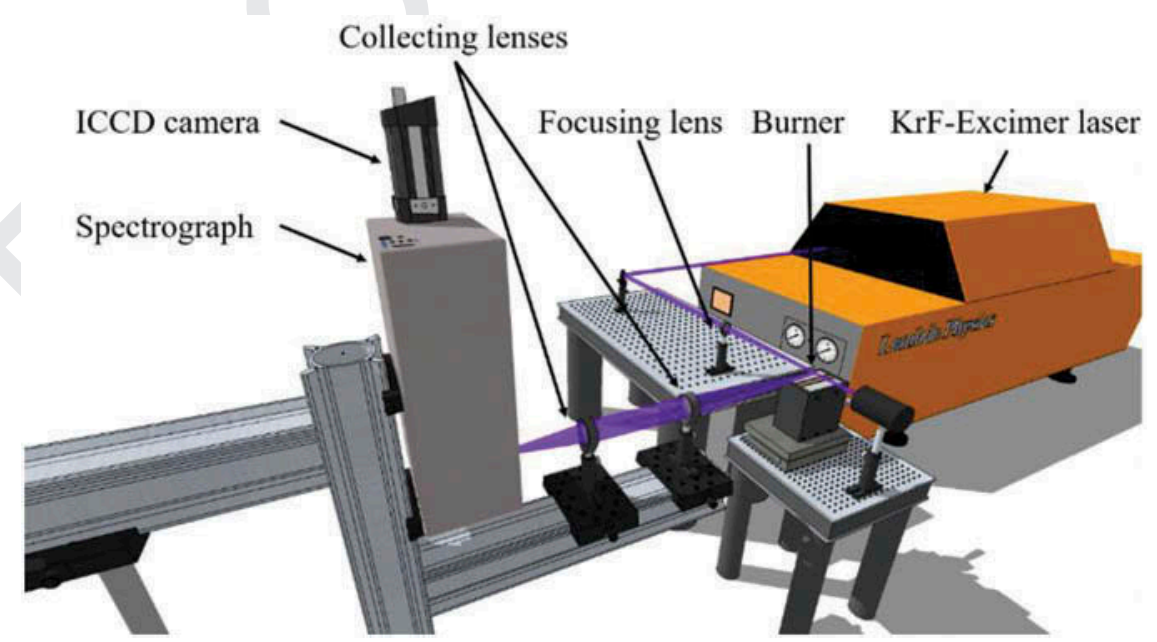

Figure 2. Optical setup for one-dimensional simultaneous Rayleigh and Raman signal detection. 
The inlet slit of the spectrograph is aligned such that the $12-\mathrm{mm}$ long slit is parallel to the beam path. In order to allow sufficient signal intensity for the single-shot analysis, the inlet slit opening is set to $0.775 \mathrm{~mm}$. The spectrograph is a Chromex SP250 with $\mathrm{f} / 4$ and features a holographic grating with 1800 grooves/mm blazed at $250 \mathrm{~nm}$. The arrangement allows the detection of a 10-mm long beam segment. A single intensified 12-bit CCD camera (LaVision, Dynamight) with $512 \times 512$ pixel is used to simultaneously detect the Rayleigh and Raman signals. The arrangement ensures a spatial resolution of $45.25 \mathrm{pixel} / \mathrm{mm}$ and a wavelength resolution of $17.86 \mathrm{pixel} / \mathrm{nm}$ resulting in a detected wavelength range from 248 to $275 \mathrm{~nm}$. Thereby, the Rayleigh line and the Raman lines from $\mathrm{CO}_{2}, \mathrm{O}_{2}, \mathrm{~N}_{2}, \mathrm{CH}_{4}$, and $\mathrm{H}_{2} \mathrm{O}$ were mapped on the detector. For data evaluation, the $10-\mathrm{mm}$ long probe segment of the laser beam is separated in 11 single volumes with dimensions of $0.775 \times 0.4 \times 0.2 \mathrm{~mm}$. For background signal reduction, the gating time of the intensifier is set to $100 \mathrm{~ns}$ and the signal collection starts instantaneously with the laser beam emission. In order to avoid a saturation of the camera by the Rayleigh signal, a quartz glass cuvette containing a mixture of $80 \%$ butyl acetate and $20 \%$ ethanol covers the spectrograph inlet. The liquid mixture inside the cuvette works as a low-pass filter such that the Rayleigh and Raman signals are on the same intensity level. The strategy of detecting Raman and Rayleigh scattering in a single image ensures the perfect spatial matching of both signals and avoids a complicated alignment procedure.

In order to derive the local gas composition from the simultaneously collected Raman and Rayleigh signal on a single-shot basis, a calibration and post-processing routine based on the procedure of Mansour and Yung-Cheng (1996) was applied. Special care was taken to correct the Raman line cross talk. Hence, 200 Raman spectra were recorded for nitrogen $\left(\mathrm{N}_{2}\right)$, carbon dioxide $\left(\mathrm{CO}_{2}\right)$, and methane $\left(\mathrm{CH}_{4}\right)$ diluted with $\mathrm{N}_{2}$. All gas streams were issued through a heated nozzle. The temperatures covered a range from ambient condition to $650 \mathrm{~K}$. For high-temperature calibration and the cross-talk correction of the $\mathrm{H}_{2} \mathrm{O}$ Raman line, calibration measurements were performed in the hot product gas of a premixed flat flame. An iterative post-processing yielded the local gas composition and temperature. The local mixture fraction was derived from the gas composition based on Bilger et al. (1990)

$$
Z=\frac{\frac{2 Y_{C}}{W_{C}}+\frac{0.5 Y_{H}}{W_{H}}+\frac{\left(Y_{O, O}-Y_{O}\right)}{W_{O}}}{\frac{2 Y_{C, f}}{W_{C}}+\frac{0.5 Y_{H, f}}{W_{H}}+\frac{Y_{O, O}}{W_{O}}}
$$

where $Y_{C, f}$ and $Y_{H, f}$ represent the mass fraction for carbon and hydrogen atoms in the fuel, respectively, $Y_{O, O}$ is that of oxygen in the oxidizer stream. $W_{i}$ is the molecular weight of species $i$. For the validation of the detection system, measurements have been performed in a premixed $\mathrm{CH}_{4} / \mathrm{N}_{2}$ jet. Figure 3 presents the measured fuel mass fraction along the beam path and reveals differences below $5 \%$ between the set and measured $Y_{F}$.

The experimental determination of mixture fraction gradients in combination with sufficient spatial resolution is exceptionally challenging for high Reynolds number turbulent flows. In particular, high local gradients statistically occur on the small turbulent scales and hence require an extremely fine resolution. A coarse spatial resolution that is insufficient to resolve the smallest turbulent scales will therefore serve as a low-pass filter. Whereas small absolute gradients are only weakly affected, coarse resolution will bias high absolute gradients toward lower values. Measured values are therefore a lower bound for 


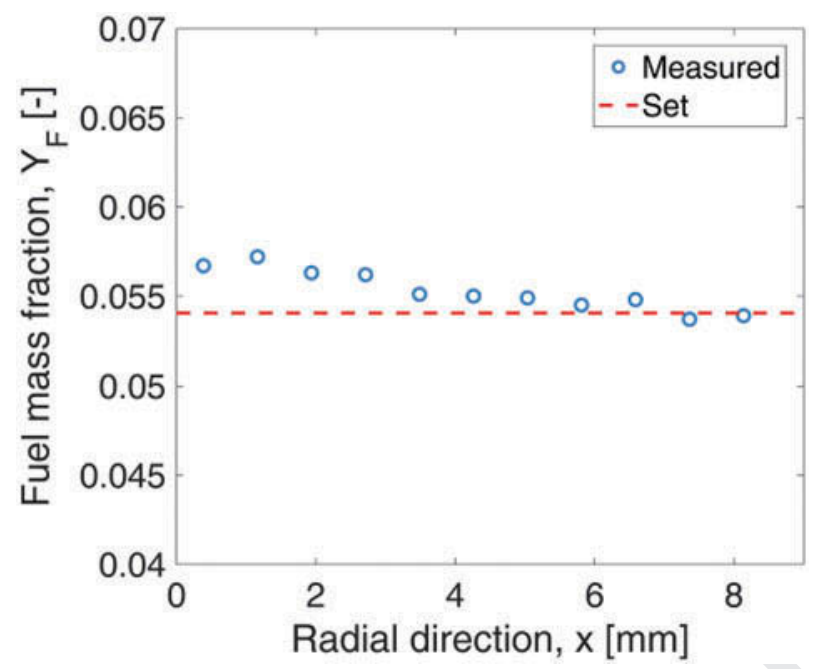

Figure 3. Comparison of adjusted and measured $\mathrm{CH}_{4}$ mass fraction in a $\mathrm{CH}_{4} / \mathrm{N}_{2}$ jet for detection system verification.

the real values. In the present study, the direction for the determination of one-dimensional mixture fraction gradients is the beam path and the spatial resolution was set to $0.775 \mathrm{~mm}$ in order to ensure a high signal-to-noise ratio. Based on the turbulence theory (Pope, 2000), it was obtained that for a jet Reynolds number of 10.000 and an approximated integral turbulence length scale of $1 / 3^{\star} d$ (Pope, 2000), the spatial resolution of $0.775 \mathrm{~mm}$ resolves $80 \%$ of the dissipation spectrum.

\section{Results and discussion}

The mixing field structure at the burner exit significantly affects the flame stability. In order to evaluate the impact of the Reynolds number (Re), the premixing level $(l / d)$, the equivalence ratio $(\Phi)$, as well as the mixing progress within the flame on the mixing field, the following experiments were performed under specific boundary conditions. Three different Reynolds numbers and three different global equivalence ratios were investigated. The simultaneous, onedimensional Raman/Rayleigh signal yields the data of the local gas composition, from which the local mixture fraction and its gradient along the beam path are derived. The Raman/Rayleigh measurements are performed at different heights, $z$, above the burner in order to extract the progress of the mixing process within the flame. Moreover, the inner nozzle was recessed to two different positions to ensure different levels of premixing at the burner exit. Overall, 54 flames were investigated. The boundary conditions are summarized in Table 1 . Note, that the same conditions have been used for the second mixing length. From the 500 single images of each boundary point, the probability density function (PDF) of the mixture fraction as well as of the gradient was determined in the unburnt region. For the statistical analysis, data points with a local temperature below $800 \mathrm{~K}$ have been considered. In order to address the effect of the mixture fraction statistics on the flame stability, the minimum and maximum values of the local mixture fraction are required. The data are obtained from the PDFs of the mixture fraction and are defined as the mixture fraction values corresponding to $10 \%$ of the PDF's peak value. 
Table 1. Overview of experimental boundary conditions for $\mathrm{l} / \mathrm{d}=4$ and $\mathrm{l} / \mathrm{d}=8$.

\begin{tabular}{llll}
\hline & $\Phi=0.8$ & $\Phi=1.0$ & $\Phi=1.1$ \\
\hline $\operatorname{Re}=6250$ & $z=1.5$ & $z=1.5$ & $z=1.5$ \\
& $z=3.0$ & $z=3.0$ & $z=3.0$ \\
$\operatorname{Re}=9375$ & $z=4.5$ & $z=4.5$ \\
& $z=1.5$ & $z=1.5$ & $z=1.5$ \\
$\operatorname{Re}=13400$ & $z=3.0$ & $z=3.0$ & $z=3.0$ \\
& $z=4.5$ & $z=1.5$ & $z=4.5$ \\
& $z=1.5$ & $z=3.0$ & $z=1.5$ \\
& $z=3.0$ & $z=4.5$ & $z=3.0$ \\
\hline
\end{tabular}

In the following, the impact of the Reynolds number, equivalence ratio, mixing progress within the flame, and premixing level on the statistics of the mixture fraction are discussed for representative flame conditions. Afterwards, the effect of inner nozzle mixing distance on the mixture fraction fluctuations and the maximum gradient is evaluated for different global equivalence ratios, different Reynolds numbers, and different measurement positions above the burner exit. The section ends with a discussion about the influence of the mixture fraction range on the flame stability employing the regime diagram for partially premixed flames.

\section{Effect of Reynolds number}

The impact of the Reynolds number on the mixing field as well as on the flame structure is evaluated for stoichiometric flame conditions. The analysis is performed through the evaluation of the PDFs of the mixture fraction and the mixture fraction gradient, see Figure 4 . The mixing length of $l / d=4$ ensures a premixing level, such that a bimodal distribution of the mixture fraction is suppressed. It is worth noting that the mixture fraction field fluctuates over a wide range inside and outside the flammability limits (Figure 4(a)). This characteristic has been found for all flame conditions. Comparing the mixture fraction distributions at Reynolds numbers $\mathrm{Re}=9375$ and $\mathrm{Re}=13400$, the impact of the increased Reynolds number on the mixing field is found to be minor, which is attributed to identical air/fuel velocity ratios. From a similar point of view, there are two

a)

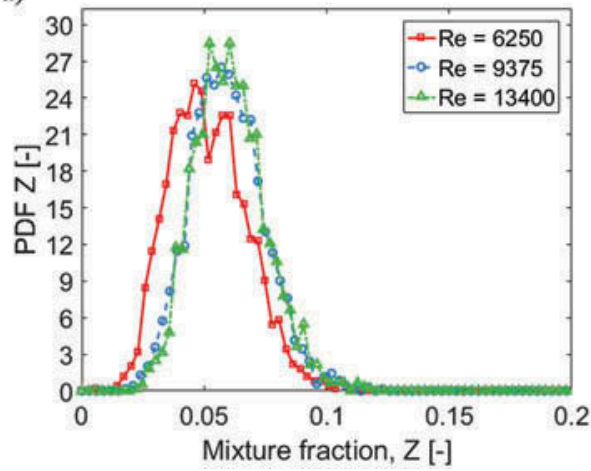

b)

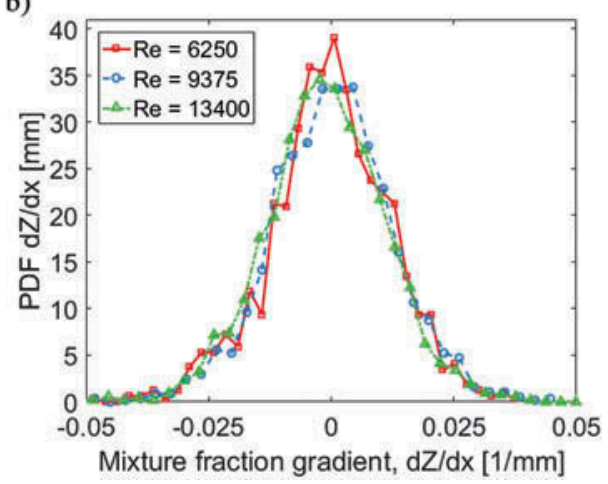

Figure 4. Variation of Reynolds number, $\Phi=1.0, z=3 \mathrm{~mm}, I / d=4$; (a) PDF of mixture fraction; (b) PDF of mixture fraction gradient. 
Reynolds numbers, i.e. for the fuel and air stream. Since both of them are changed in the same way to maintain the global stoichiometry of the flame constant with $\Phi=1.0$, the velocity ratio between fuel and air remains unchanged with increasing Reynolds number. Therefore, the shear layers between the flows, as the driving mechanism for the mixing process, are presumed to be similar and mixing of fuel and air is not affected as soon as the Reynolds number is high enough.

However, for the lowest Reynolds number $(\mathrm{Re}=6250)$, the mixture fraction distribution is slightly shifted to the leaner side, although the overall equivalence ratio is 1.0 for all cases. While for the Reynolds numbers $\mathrm{Re}=9375$ and $\mathrm{Re}=13400$ a turbulent flow is achieved in the mixing area of the burner and at the burner exit, the lowest Reynolds number is below the mixing transition. The decreased turbulence intensity lowers the possibility of fuel rich pockets to pass the detection field, which is centered at the edge of the main slot. The statistics of the one-dimensional mixture fraction gradients for the three Reynolds numbers are shown in Figure 4(b). Although the PDF of the mixture fraction gradient might be biased toward lower absolute values due to coarse spatial resolution, the differences of the gradient distribution are insignificant resulting in similar dissipation rates.

\section{Effect of global equivalence ratio}

The effect of equivalence ratio on the flame and mixing characteristics is discussed in the following. The premixing length $(l / d=4)$, the Reynolds number $(\operatorname{Re}=9375)$, and the measurement position $z=3 \mathrm{~mm}$ remain constant for the three conditions of equivalence ratio. In order to adjust the equivalence ratio while keeping the Reynolds number constant, the fuel mass flow is increased and the air flow is decreased. The higher fuel flow rate increases the mixture fraction. This effect is reflected in the mixture fraction distribution by a shift of the PDF peak toward higher mixture fractions (Figure 5(a)). Moreover, the variation of the air and fuel flow rate induces changes in the velocity ratio of both flows. With increasing equivalence ratio, the velocity ratio is lowered accompanied with decreased shear between the jets. As the shear rates are the driving mechanism for

a)

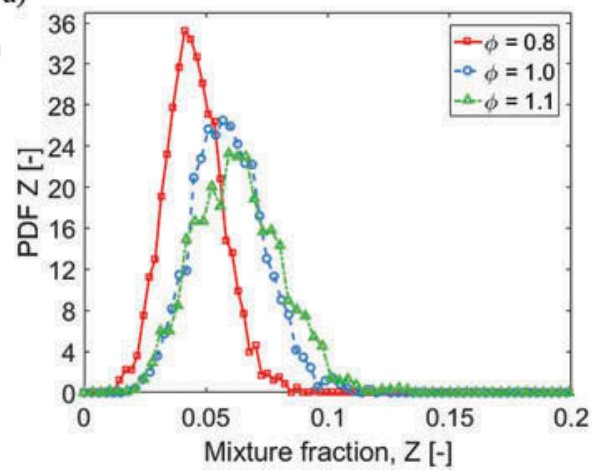

b)

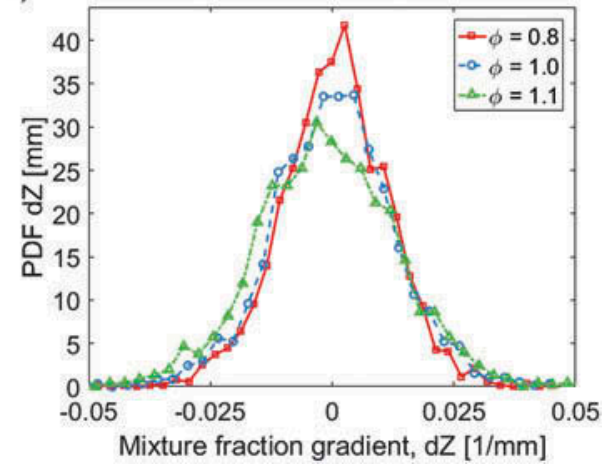

Figure 5. Variation of equivalence ratio $\Phi$, Reynolds number, $\operatorname{Re}=9375, z=3 \mathrm{~mm}, I / d=4$. 
the mixing process, a reduced mixing level at the burner exit is revealed from the wider mixture fraction distribution for increased equivalence ratios, Figure 5.

The narrow distribution for the lean case indicates a more premixed air/fuel jet. Moreover, the higher one-dimensional mixture fraction gradients and the wider PDF of the gradients for the increased equivalence ratio indicate a higher inhomogeneity at the outlet and emphasize the conclusion of the lower premixing level (Figure 5(b)). Considering that the potential bias of the mixture gradients yields lower absolute gradients, the broadening of the PDFs at high equivalence ratios might be even larger.

\section{Effect of mixing progress in flame}

The level of premixing at the burner exit highlights the evaluation of the global characteristics of the flame. The local mixture fraction distribution in the flame region has significant impact on the local flame behavior. The mixing of fuel and air at the burner outlet is dominantly influenced by the burner design. Mixing proceeds downstream of the slot exit, and the premixing level locally affects the flame. Therefore, a partially premixed flame might cover several stability regimes. In order to discuss the mixing progress in the unburnt flame area, local mixture fraction values have been determined at three heights above the burner exit. The PDFs of mixture fraction and one-dimensional mixture fraction gradients for the three measurement positions are shown in Figure $6(\mathrm{a}, \mathrm{b})$, respectively. As shown in Figure 6(a), the mixture fraction PDF obtained at $1.5 \mathrm{~mm}$ above the burner exit indicates the highest fluctuation of the mixture fraction range. Compared to the other distributions at $z=3 \mathrm{~mm}$ and $z=4.5$, the mixture fraction PDF at $z=1.5 \mathrm{~mm}$ is centered at a lower mixture fraction. This effect is attributed to the alignment of the detection field at the outer edge of the main slot covering a wide section of the air path inducing an enhanced possibility of detecting very lean pockets. With increasing distance from the burner outlet, the mixing becomes more homogeneous resulting in an increase of averaged mixture fraction within the detection area. As a result, the mixture fraction distribution is shifted toward higher mixture fraction values. The increasing homogeneity of the fuel air stream with increasing height above the burner is also manifested in the decreasing broadening of the PDF at $z=3 \mathrm{~mm}$ and $z=4.5 \mathrm{~mm}$. The

a)

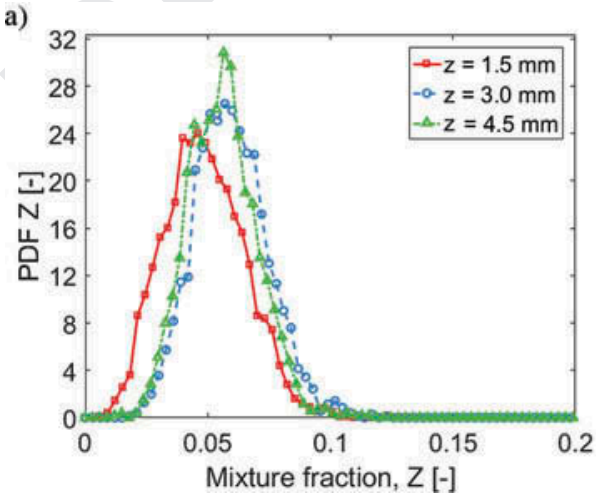

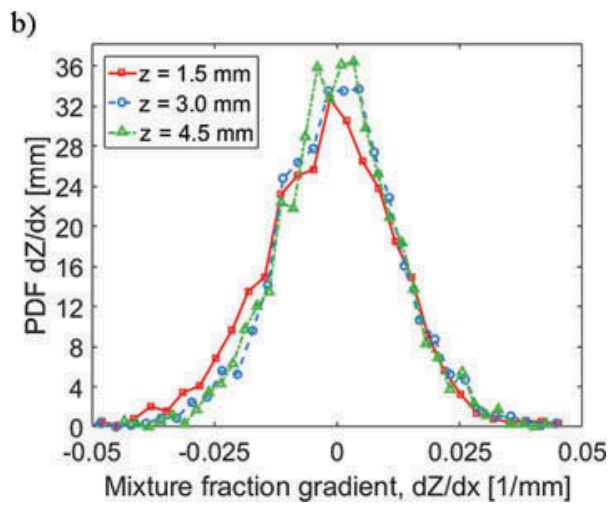

Figure 6. Variation of measurement position $(z)$ above the burner exit, $\operatorname{Re}=9375, \Phi=1.0$. 
highest fluctuations of the mixture fraction field are found at $z=1.5 \mathrm{~mm}$. Furthermore, 280 the statistical distribution of the one-dimensional mixture fraction gradients is the widest at the lowest measurement position (Figure 6(b)). The higher gradients at $z=1.5 \mathrm{~mm}$ indicate an increased inhomogeneity. With increasing distance from the burner exit, fuel and air become homogeneously mixed.

\section{Effect of mixing length}

The level of premixing at the burner outlet strongly depends of the internal design of the burner. In this study, the burner allows to vary the distance for air and fuel premixing upstream of the burner exit. Two different mixing lengths $l / d=4$ and $l / d=8$ were investigated, while the Reynolds number $\operatorname{Re}=9375$, global equivalence ratio $\Phi=1.0$, and measurement position $z=3 \mathrm{~mm}$ remain constant. The measured mixture fraction PDFs and the one-dimensional mixture fraction gradient PDFs are presented in Figure 7. The significant effect of the mixing length on the fuel/air premixing level is revealed by the statistics of the mixture fraction and its gradient.

For $l / d=4$, the mixture fraction fluctuates over a wide range inside and outside the flammability limit. The increase of the mixing length results in an enhanced premixing and therefore reduces the fluctuations of the mixture fraction to a narrow range around the stoichiometric mixture fraction, as shown in Figure $7\left(b_{2}\right)$. Note that the mean mixture fraction for the $l / d=4$ case is below the stoichiometric fraction. This observation has been discussed in detail in the previous section and is mainly attributed to the alignment of the detection field to the burner.

The one-dimensional mixture fraction gradients emphasize the findings of a more homogeneous fuel-air mixture at the burner outlet with increasing mixing length. For the shorter mixing length, substantially higher gradients are observed confirming the lower level of premixing compared to the longer mixing length, as shown in Figure 7(b).

The subsequent analysis of the effect of the premixing level on the mixture fraction variation for a broad range of boundary conditions is performed with respect to the mixture fraction PDF broadness $(\Delta Z)$ defined here as the difference between the $10 \%$ and

a)

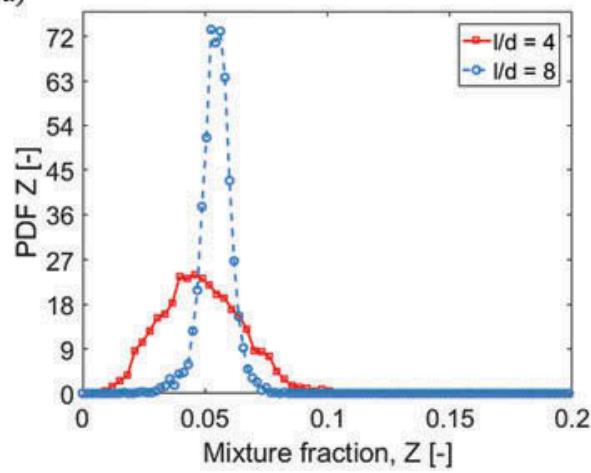

b)

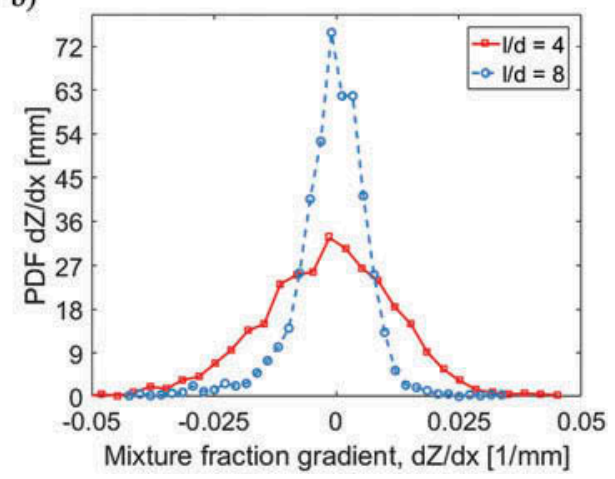

Figure 7. Variation of mixing length $/ / d, \operatorname{Re}=9375, \Phi=1.0, z=1.5 \mathrm{~mm}$; (a) PDF of mixture fraction; (b) PDF of one-dimensional mixture fraction gradient. 
$90 \%$ limits of the mixture fraction PDF peak value. Small values of $\Delta Z$ are inherently connected with a more premixed flow, whereas higher $\Delta Z$ values indicate a lower premixing level. Figure 8 presents the dependence of $\Delta Z$ on equivalence ratio, Reynolds number, and measurement position for both premixing lengths.

For constant Reynolds number and measurement position, an increase of $\Delta Z$ with increasing equivalence ratio is demonstrated for both premixing lengths in Figure 8(a). Significant lower values of $\Delta Z$ for $l / d=8$ disclose the higher degree of premixing compared to $l / d=4$. The increasing broadness of the mixture fraction distribution is mainly attributed to the increased velocity differences of the air and the fuel jet with lower equivalence ratio causing higher shear between the flows and thereby enhance the mixing between these two flows.

Referring to Figure 8(b), the impact of Reynolds number variation on the $\Delta Z$ is indistinct for $l / d=8$. For $l / d=4$, a minor reduction of $\Delta Z$ with increasing Reynolds number is obtained. Similar trends are observed for changes in the measurement position in Figure 8. While the mixture fraction fluctuations are lowered downstream of the burner exit for $l / d=4$, the flow is nearly fully mixed for $l / d=8$ such that $\Delta Z$ remains constant with increasing $z$.

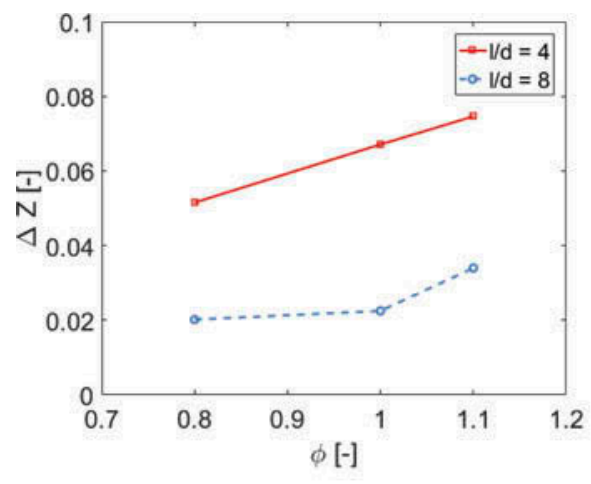

a) $\operatorname{Re}=9375, \mathrm{z}=1.5 \mathrm{~mm}$

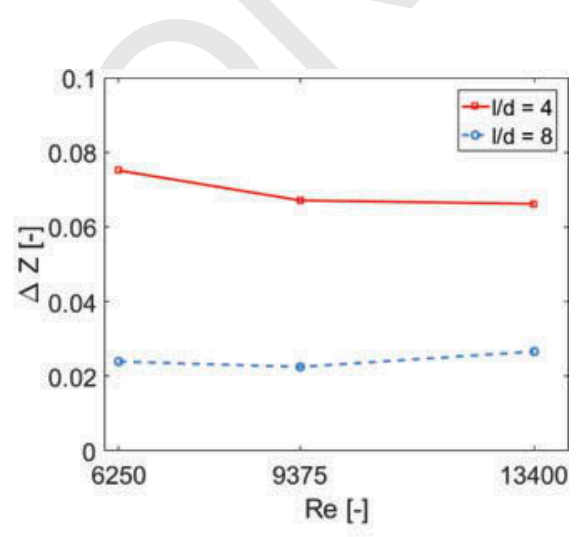

b) $\phi=1.0, \mathrm{z}=1.5 \mathrm{~mm}$

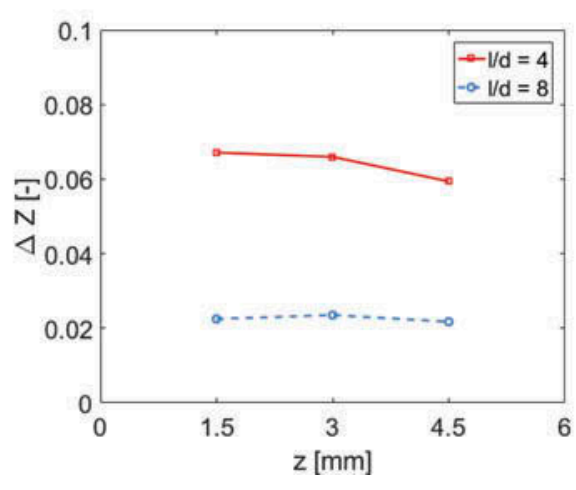

c) $\phi=1.0, \operatorname{Re}=9375$

Figure 8. $\Delta Z$ for different levels of mixture fraction in dependence of equivalence ratio, Reynolds number, and measurement position. 
Impact of equivalence ratio, Reynolds number, mixing progress, and mixing length on partially premixed flame stability

Partially premixed flames are characterized by fluctuations of the mixture fraction upstream of the reaction zone that have significant effect on the flame structure and stability. In order to classify the impact of mixture fraction distribution on partially premixed flames, Mansour (2016) has recently proposed a new regime diagram. In this work, the diagram is utilized to evaluate the effect of $\Phi, \mathrm{Re}$, mixing length, and measurement position on the flame stability. The regime diagram distinguishes eight different regimes and is shown in Figure 9. The minimum $\left(Z_{\text {min }}\right)$ and maximum $\left(Z_{\text {max }}\right)$ mixture fraction, as well as the lean $\left(Z_{\mathrm{L}}\right)$ and rich $\left(Z_{\mathrm{R}}\right)$ flammability limits are used to separate the regimes. $Z_{\min }$ and $Z_{\max }$ are determined as the $10 \%$ and $90 \%$ limits of the mixture fraction PDF peak value. According to Mansour (2016), $Z_{\mathrm{L}}$ and $Z_{\mathrm{R}}$ for methane are 0.0284 and 0.0892 , respectively. $\bar{Z}_{\mathrm{mm}}$ is defined as the mean of minimum and maximum mixture fraction and $\bar{Z}_{\mathrm{LR}}$ is the mean of lean and rich flammability limit. $\Delta Z_{\mathrm{mm}}$ is the difference between $Z_{\max }$ and $Z_{\min }$ and $\Delta Z_{\mathrm{mm}}$ represents the difference between $Z_{\mathrm{R}}$ and $Z_{\mathrm{L}}$. Mansour et al. (2017a) discussed the correlation between the location of the data points within the regime diagram and the flame structure and stability. The level of spatial and temporal fluctuations of the mixture fraction affects the scatter of the data points in the regime diagram and consequently affects the flame stability and structure.

Figure 9 illustrates the effect of equivalence ratio variation on flame stability. The different symbols represent different equivalence ratio, the symbol color indicates the mixing length, $l / d$. An increase of the mixing length leads to a higher fuel/air premixing level which is accompanied by a reduction of $R_{\Delta}$. As the global equivalence ratios are the same for both mixing lengths, also the normalized mean mixture fractions, $R_{\bar{Z}}$, remain unchanged with the mixing length. However, $R_{\bar{Z}}$ changes with the global equivalence ratio. With increasing global $\Phi$, also the mean mixture fraction increases. For $l / d=8$ (blue symbols), all flames are located within the most stable regime as the mean mixture fraction

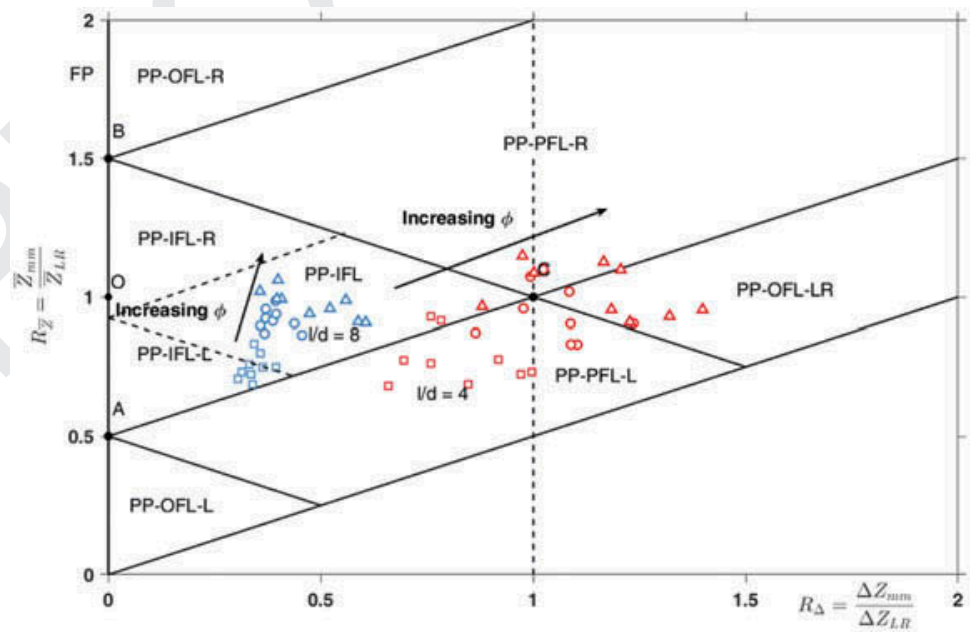

Figure 9. Regime diagram to evaluate effect of $\Phi$ on flame stability. Red symbols: $I / d=4$, blue symbols $I / d=8 ; \Phi=0.8$ : squares, $\Phi=1.0$ : circles, $\Phi=1.1$ : triangles. 
as well as the minimum and maximum mixture fractions are within the flammability limit. Hence, local flame extinction is inhibited (Mansour, 2016; Mansour et al., 2017a). For the shorter mixing length, most of the flames are located partly inside and partly outside the flammability limits. Whereas the lean flames exceed the lean flammability limit and are located in PP-PFL-L, the globally rich flames mostly pass the rich flammability limits (PPPFL-R and PP-PFL-RL). A global trend of increasing fluctuations and higher mixture fraction with an increase of the equivalence ratio is observed.

For $\Phi=1.1$ at $l / d=4$, the flames cover a wide range outside both lean and rich flammability limits (PP-OFL-LR) with some data outside the rich limit (PP-PFL-R). A global trend of increasing fluctuations and higher mixture fraction with an increase of the equivalence ratio is observed. This behavior is also found for more premixed flames $(l / d=8)$. However, the fluctuations in the mixture fraction field grow faster for the less premixed flames. This fluctuation increase is attributed to the smaller velocity gradients within the burner slot for the rich flame conditions resulting in decreased shear forces and therefore in degraded mixing. This effect is more pronounced for the less premixed flame conditions, since the longer mixing length $(l / d=8)$ compensates decreased shear forces with higher equivalence ratio.

The regime diagram shown in Figure 10 illustrates the effect of the Reynolds number on the flame stability. A distinct correlation between Reynolds number and flame stability is not evident in Figure 10. While the velocity at the burner exit is increased with higher Reynolds number, the velocity ratio between fuel and air flow upstream of the burner exit is not influenced. This suggests that the Reynolds number has only a marginal impact on the internal mixing process within the burner. This finding is in good agreement with the observations of (Mansour et al., 2017a).

The mixing of fuel and air proceeds downstream of the burner exit and enables the flame to cover different flame stability regimes. In order to evaluate the effect of the mixing progress downstream of the burner exit, measurements have been performed at different heights above the burner. The corresponding mixture fraction fluctuations and

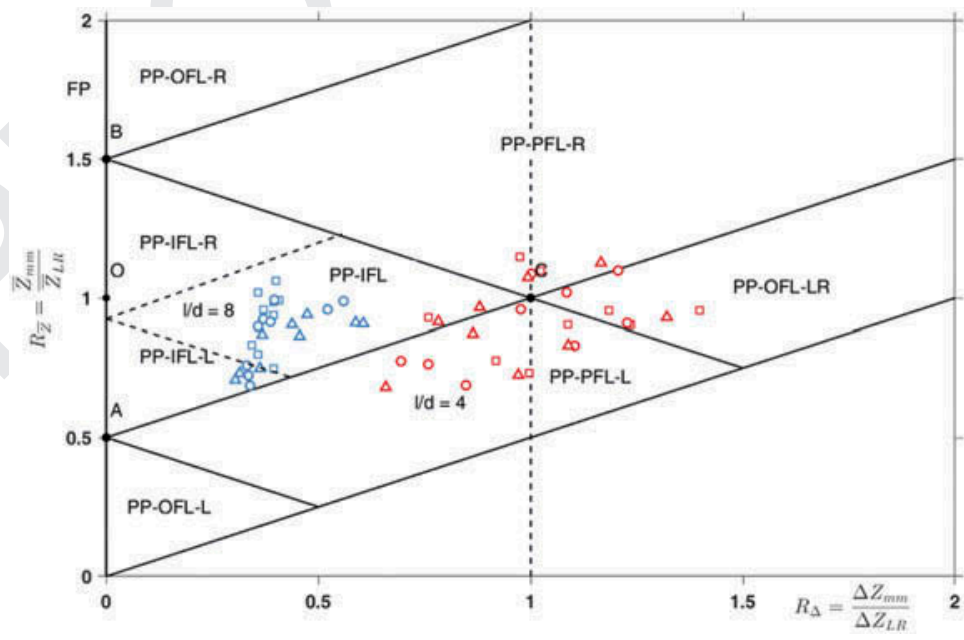

Figure 10. Effect of Reynolds number on flame stability. Red symbols: $I / d=4$, blue symbols: $I / d=8$; $\operatorname{Re}=6250:$ squares, $\operatorname{Re}=9375:$ circles, $\operatorname{Re}=13400$ : triangles. 


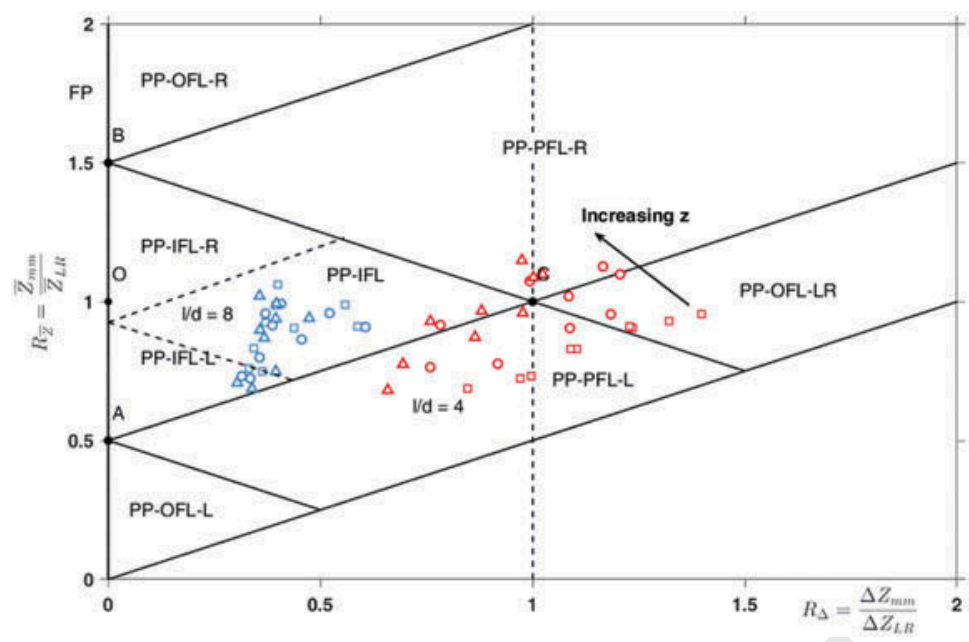

Figure 11. Effect of mixing progress on flame stability. Red symbols: $I / d=4$, blue symbols: $I / d=8$; $z=1.5 \mathrm{~mm}$ : squares, $z=3 \mathrm{~mm}$ : circles, $z=4.5 \mathrm{~mm}$ : triangles.

mean mixture fraction at different heights above the burner are shown in the regime diagram illustrated in Figure 11. For the mixing length $l / d=8$, fuel and air are almost homogeneously mixed at the burner exit. The fluctuations of the mixture fraction are found to be minor and a further minimization of the fluctuation is not observed with increasing distance from the burner exit. For $l / d=4$, fuel and air are partially premixed at the burner exit indicated by the fluctuations of the mixing field. With increasing distance from the burner exit, the fluctuations progressively decrease with increasing distance from the burner. For $z=1.5 \mathrm{~mm}$, most flames are partly inside and partly outside the flammability limits and partly exceed the lean flammability. With increased distance, the fluctuations become minor and the overall normalized averaged mixture fraction is increased. The fuel air stream is more homogeneous at $z=3 \mathrm{~mm}$ and $z=4.5 \mathrm{~mm}$, and the data points are shifted to the stable regime (PP-IFL). Moreover, the increase of the average mixture fraction yields a transfer to the stability regimes, in which the unburnt mixture is partly inside the flammability limit and partly exceeds the rich flammability limit. Note that the effect of the increased stability is not solely attributed to the change in the measurement position but also is affected by the change in the global equivalence ratio.

\section{Conclusions}

In this study, the mixing field of partially premixed flames was investigated in a slot burner configuration. The local mixture fractions and the one-dimensional mixture fraction gradients were extracted from simultaneous, one-dimensional Raman and Rayleigh scattering measurements. A total of 54 partially premixed flames were investigated. Statistics of the mixture fraction were employed to address the effects of Reynolds number, global equivalence ratio, mixing progress within the flame, and mixing length on the mixing field in the unburnt flame zone and on the flame stability. The increase of the mixing length, defined as the free distance for air and fuel to mix upstream of the burner exit, is found to significantly reduce the mixture fraction fluctuations as well as the 
mixture fraction gradients. The reduction of the global equivalence ratio induces an enhanced mixing due to higher velocity ratio of the fuel and air flows. Moreover, the premixing level within the flame is increased with ascending distance from the burner exit. A marginal effect of the Reynolds number on the mixing field is revealed. A recently proposed regime diagram for partially premixed flames based on the mean mixture fraction and the mixture fraction fluctuation was used to evaluate the flame stability. For the long mixing length, all flames are located in the most stable regime. For the decreased mixing length, the mixture fraction distribution partly exceeds the flammability limit. With the increased distance from the burner exit, the mixture fraction fluctuations are minimized, which leads to more stable flame. An increase of the equivalence ratio results in a shift of the stability regime from the lean to the rich regimes. Similar to fuelair mixing, also flame stability is barely affected by the Reynolds number.

\section{Acknowledgments}

This work was performed within the Cluster of Excellence "Tailor-Made Fuels from Biomass," which is funded by the Excellence Initiative of the German federal state governments to promote science and research at German universities. The support of the design office and workshop of the Institute for Combustion Technology in the burner development and setup are gratefully acknowledged.

\section{References}

Aleiferis, P.G., et al. 2004. The nature of early flame development in a lean-burn stratified-charge spark-ignition engine. Combust. Flame., 136(3), 283-302.

Barlow, R.S., et al. 2009. Application of Raman/Rayleigh/LIF diagnostics in turbulent stratified flames. Proc. Combust. Inst., 32 I(1), 945-953. doi:10.1016/j.proci.2008.06.070.

Barlow, R.S., et al. 2017. On defining progress variable for Raman/Rayleigh experiments in partiallypremixed methane flames. Combust. Flame., 179, 117-129. http://linkinghub.elsevier.com/ retrieve/pii/S0010218017300275.

Bilger, R.W., Stårner, S.H., and Kee, R.J. 1990. On reduced mechanisms for methane-air combustion in nonpremixed flames. Combust. Flame., 80(2), 135-149. http://www.sciencedirect.com/ science/article/pii/0010218090901228.

Borghi, R. 1988. Turbulent combustion modelling. Prog. Energy Combust. Sci., 14(4), 245-292. [Accessed March 27, 2017]. http://linkinghub.elsevier.com/retrieve/pii/0360128588900159.

Branco, J., Coelho, P.J., and Costa, M. 2016. Experimental and numerical investigation of turbulent diffusion flames in a laboratory combustor with a slot burner. Fuel, 175, 182-190. http://www. sciencedirect.com/science/article/pii/S0016236116001678.

Brands, T., et al. 2014. Effects of mixture stratification on ignition and combustion in a GCAI engine. SAE Int. J. Engines, 7(2), 714-729. doi:10.4271/2014-01-1270.

Cheng, T.S., et al. 2012. Laser Raman measurements of temperature and species concentration in swirling lifted hydrogen jet diffusion flames. Int. J. Hydrogen Energy, 37(9), 7900-7911. http:// www.sciencedirect.com/science/article/pii/S0360319912003400.

Dec, J.E. 2009. Advanced compression-ignition engines - Understanding the in-cylinder processes. Proc. Combust. Inst., 32 II(2), 2727-2742. doi:10.1016/j.proci.2008.08.008.

Elbaz, A.M., et al. 2016. The flow field structure of highly stabilized partially premixed flames in a concentric flow conical nozzle burner with coflow. Exp. Thermal Fluid Sci., 73, 2-9. http://www. sciencedirect.com/science/article/pii/S0894177715002277.

Elbaz, A.M., et al. 2018. Highly stabilized partially premixed flames of propane in a concentric flow conical nozzle burner with coflow. Exp. Thermal Fluid Sci. http://www.sciencedirect.com/science/ article/pii/S0894177718300372. 
El-Mahallawy, F., Abdelhafez, A., and Mansour, M.S. 2007. Mixing and nozzle geometry effects on flame structure and stability. Combust. Sci. Technol., 179(1-2), 249-263. http://www.tandfonline. com/doi/abs/10.1080/00102200600809324.

Favier, V., and Vervisch, L. 1998. Investigating the effects of edge flames in liftoff in non-premixed turbulent combustion. Symp. (Int.) Combust., 27(1), 1239-1245. http://linkinghub.elsevier.com/ retrieve/pii/S0082078498805286.

Filatyev, S.A., et al. 2005. Measured properties of turbulent premixed flames for model assessment, including burning velocities, stretch rates, and surface densities. Combust. Flame., 141(1-2), 1-21.

Fuest, F., et al. 2011. A hybrid method for data evaluation in 1-D Raman spectroscopy. Proc. Combust. Inst., 33(1), 815-822. doi:10.1016/j.proci.2010.06.064.

Fuest, F., et al. 2012. Raman/Rayleigh scattering and CO-LIF measurements in laminar and turbulent jet flames of dimethyl ether. Combust. Flame., 159(8), 2533-2562. doi:10.1016/j. combustflame.2011.11.001.

Fuest, F., et al. 2015. Quantitative acetylene measurements in laminar and turbulent flames using 1D Raman/Rayleigh scattering. Combust. Flame., 162(5), 2248-2255. doi:10.1016/j. combustflame.2015.01.021.

Huang, Y., and Yang, V. 2009. Dynamics and stability of lean-premixed swirl-stabilized combustion. Prog. Energy Combust. Sci., 35(4), 293-364. http://www.sciencedirect.com/science/article/ pii/S0360128509000094.

Joedicke, A., Peters, N., and Mansour, M. 2005. The stabilization mechanism and structure of turbulent hydrocarbon lifted flames. Proc. Combust. Inst., 30(1), 901-908. doi:10.1016/j. proci.2004.08.031.

Lee, T.W., Fenton, M., and Shankland, R. 1997. Effects of variable partial premixing on turbulent jet flame structure do. Combust. Flame., 109, 536-548.

Li, B., et al. 2009. Experimental and numerical study of a conical turbulent partially premixed flame. Proc. Combust. Inst., 32 II, 1811-1818.

Mansour, M.S. 2000. A concentric flow conical nozzle burner for highly stabilized partially premixed flames. Combust. Sci. Technol., 152(1), 115-145. doi:10.1080/00102200008952130.

Mansour, M.S. 2016. Classification of the mixing field of partially premixed flames using regime diagram. Combust. Sci. Technol., 188(4-5), 667-683. doi:10.1080/00102202.2016.1139392.

Mansour, M.S., Bilger, R.W., and Stårner, S.H. 1989. A reverse flow reactor for turbulence/chemistry interaction studies. Combust. Sci. Technol., 65(1-3), 83-101. doi:10.1080/00102208908924043.

Mansour, M.S., Chen, Y.C., and Peters, N. 1999. Highly strained turbulent rich methane flames stabilized by hot combustion products. Combust. Flame., 116(1-2), 136-153.

Mansour, M.S., et al. 2017a. Effect of the mixing fields on the stability and structure of turbulent partially premixed flames in a concentric flow conical nozzle burner. Combust. Flame., 175, 180200. doi:10.1016/j.combustflame.2016.08.032.

Mansour, M.S., Elbaz, A.M., and Samy, M., 2012. The stabilization mechanism of highly stabilized partially premixed flames in a concentric flow conical nozzle burner. Exp. Therm Fluid Sci., 43, 55-62. http://www.sciencedirect.com/science/article/pii/S0894177712000842.

Mansour, M.S., et al. 2017b. A concentric flow slot burner for turbulent flames of partially premixed and inhomogeneous mixtures of gaseous fuels. In 10th U. S. National Combustion Meeting Organized by the Eastern States Section of the Combustion Institute.

Mansour, M.S., and Yung-Cheng, C. 1996. Line Raman, Rayleigh, and laser-induced predissociation fluorescence technique for combustion with a tunable $\mathrm{KrF}$ excimer laser. Applied Optics Publ: Opt. Soc. America 20 July, 35(21), 4252-4260.

Masri, A.R. 2015. Partial premixing and stratification in turbulent flames. Proc. Combust. Inst., 35 (2), 1115-1136. doi:10.1016/j.proci.2014.08.032.

Meares, S., et al. 2015. Stabilization of piloted turbulent flames with inhomogeneous inlets. Proc. Combust. Inst., 35(2), 1477-1484. doi:10.1016/j.proci.2014.05.071.

Meares, S., and Masri, A.R. 2014. A modified piloted burner for stabilizing turbulent flames of inhomogeneous mixtures. Combust. Flame., 161(2), 484-495. doi:10.1016/j.combustflame.2013.09.016.

Peters, N. 2000. Turbulent Combustion, Cambridge University Press, Cambridge.

Pope, S.B. 2000. Turbulent Flows, Cambridge University Press, Cambridge. 
Raffius, T., et al. 2017. Flame-temperature, light-attenuation, and CO measurements by spontaneous Raman scattering in non-sooting diesel-like jets. Combust. Flame., 176, 104-116. http://linkin ghub.elsevier.com/retrieve/pii/S0010218016302978.

Wehrmeyer, J.A., Cheng, T.-S., and Pitz, R.W. 1992. Raman scattering measurements in flames using a tunable KrF laser. Appl. Opt., 31(10), 1495-1504. http://ao.osa.org/abstract.cfm?URI=ao31-10-1495.

Yan, B., et al. 2010. Structures and stabilization of low calorific value gas turbulent partially premixed flames in a conical burner. Exp. Thermal Fluid Sci., 34(3), 412-419. http://www. sciencedirect.com/science/article/pii/S0894177709001563. 